\title{
Betonarme Yapıların Deprem Etkisi Altında Performans Analizlerinin Yapılması ve Güçlendirilmesi
}

\author{
Jülide YÜZBAŞI" ${ }^{* 1}$ Hüseyin R. YERLí ${ }^{1}$ \\ ${ }^{1}$ Çukurova Üniversitesi, Mühendislik Fakültesi, İnşaat Mühendisliği Bölümü, Adana
}

$\ddot{O} \mathbf{z}$

Geliş tarihi: 25.06.2018 Kabul tarihi: 29.06.2018

\begin{abstract}
Ülkemiz üzerinde etkin fay hatlarının bulunduğu bir yapıya sahiptir. Yaşanılan son depremler ülkemizde inşa edilmiş birçok yapının gerekli deprem güvenliği koşullarını sağlayamayacak düzeyde olduğunu göstermiştir [1-4]. Bu durum mevcut yapıların dinamik etki altındaki davranışlarını incelemeyi gerekli kılmaktadır. Bu çalışmada, mevcut yapılar sahip oldukları fiziksel koşullar göz önünde bulundurularak modellenmiş ve günümüz şartlarında farklı deprem düzeyleri etkisi altındaki performansları analiz edilmiştir. FEMA-356'ya paralel olarak revize edilen Türk Deprem Yönetmeliği'ne (TDY-2007) dayanan bir performans değerlendirmesi yapılmıştır [5-6]. Yapılan performans analizleri sonucunda yapıların depreme karşı yeterliliği ve yapıldığı dönem sonrasında meydana gelmiş olan gelişmelere uygunluğu irdelenmiştir. Performans yetersizliği durumunda, yapı emniyeti ve ekonomik koşullar dikkate alınarak, yapıya uygulanacak işlemler hakkında verilecek en uygun kararın ne olduğu belirlenmiştir. Mevcut yapıların deprem durumunda güvenli olup olmadığı kontrol edilmiş̧ir. Gerekli hallerde güçlendirme çalışmalarının projelendirilmesi yapılmıştır [7]. Böylelikle ileride yaşanabilecek can ve mal kayıplarının önlenmesi amaçlanmıştır.
\end{abstract}

Anahtar Kelimeler: Yapıların güçlendirilmesi, Deprem mühendisliği, Yap1 dinamiği, Performans analizi, Yapı güvenliği

\section{Performance Analysis and Strengthening of Reinforced Concrete Structures under Earthquake Impact}

\begin{abstract}
Our country has a structure with active fault lines on it. Recent earthquakes have shown that many structures built in our country are not able to provide necessary earthquake safety conditions [1-4]. This makes it necessary to examine the behavior of existing structures under the dynamic influence. In this study, existing structures are modeled considering the physical conditions they have and their performances under different earthquake levels in today's conditions are analyzed. A performance assessment was performed based on the Turkish Earthquake Code (TEC-2007), which was revised in parallel on the FEMA-356 [5-6]. As a result of the performance analyzes made, the sufficiency of the structures against earthquakes and their suitability for the developments that took place after the time they were built was discussed. In case of performance inadequacy, it is determined what is the most appropriate decision to be taken regarding to the process that will be applied to the structure, taking into account the structural safety and economic conditions. Existing constructions have been checked to
\end{abstract}

"Sorumlu yazar (Corresponding author): Jülide YÜZBAŞı, jyuzbasi@cu.edu.tr 
determine if they are safe in case of an earthquake. Projects of strengthening work have been carried out where it is necessary [7]. Thus, it is aimed to prevent any loss of life and property that can potentionally be experienced in the future.

Keywords: Strengthening of structures, Earthquake engineering, Structural dynamics, Performance analysis, Construction safety

\section{GİRIS}

Ülkemizin deprem kuşaklarının üzerinde bulunması, yapıların projelendirilmesi ve inşa edilmesi sırasında dinamik etkilerin göz önüne alınmasını kaçınılmaz kılmaktadır. Geçmiş yönetmeliklere göre yapılan mevcut yapıların önemli bir kısmı günümüzde geçerli olan yönetmelik koşullarını sağlayamamaktadır. Ayrıca projesine uygun bir şekilde yapılmayan yapılar da günümüzde deprem performansı açısından yetersiz kalabilmektedir.

Türk deprem yönetmeliği, yeni yapılacak binalarda depreme dayanıklılığı esas alacak bir tasarım yapılmasını öngörmektedir [8]. Özellikle deprem sonrası ilk öncelikli kullanılacak yapıların (hastane, okul vs.) güvenliğinin ve deprem anındaki performanslarının bilinmesi gerekmektedir. Mevcut yapıların deprem güvenliğinin hedeflenen düzeye yükseltilebilmesi amacıyla onarım ve güçlendirme çalışmalarına başvurulmaktadır.

Deprem etkisi altındaki bir yapının davranışını belirleyebilmek için yapıya ait malzeme parametrelerinin tespiti ve sistem elemanlarının konumlarının belirlenmesi esastır. Doğru bir model kurulumu yapıya ait özelliklere olabildiğince yakın olan parametrelerin kullanılması ile mümkün olacaktır. Böylelikle model kurulum aşamasında girilen veriler yapının gerçek durumunu yansıttığı için binanın deprem etkisi altındaki davranışını en iyi şekilde sergileyecek sistem modeli elde edilmiş olacaktır.

Yapı hakkında bilgilerin toplanması ve model kurulumu aşamalarından sonra performans analizi gerçekleştirilir. Yap1 deprem performansında yetersizlik söz konusu ise güçlendirme projesi hazırlanır. Ancak hazırlanan projenin uygulamaya konulması veya gerekirse yapının yıkılıp baştan yapılması, genel bir teamül çerçevesinde yapılacak ekonomik bir değerlendirme sonucu alınan karar ile mümkün olacaktır.

Yapılan çalışmada 1975 Deprem Yönetmeliğine göre projelendirilmiş ve inşa edilmiş olan Adana ili, Çukurova Sabancı İlkokulu ve Çukurova Vakıfbank Ortaokulu A Blok Binasının performans analizleri incelenmiştir. Elde edilen veriler sonucunda yapılar Türk Deprem Yönetmeliğinin ilgili hükümleri doğrultusunda değerlendirilecek, deprem tahkikinin yapılması ve revize edilmesi kapsamında yeniden hazırlanmış olan güçlendirme projelerinin uygulamaya geçirilip/geçirilmeyeceği konuları ele alınmıştır.

Çalışmada ele alınan her iki yapı da hâlihazırda okul binası olarak kullanılmaktadır. Söz konusu yapıların mevcut durum özellikleri ve modelde kullanılacak analiz parametrelerine ait şekil ve çizelgeler aşağıda verilmektedir.

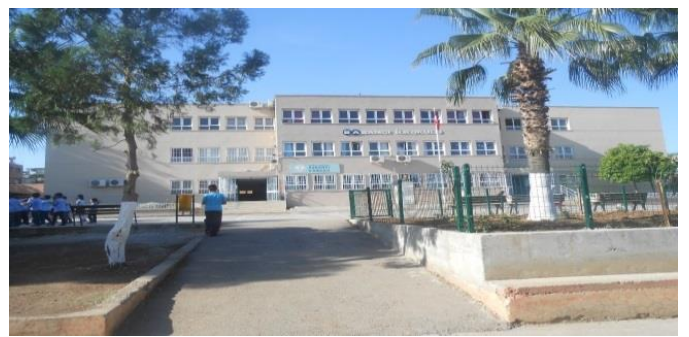

Şekil 1. Sabancı İlkokulu ön cephe görünüşü

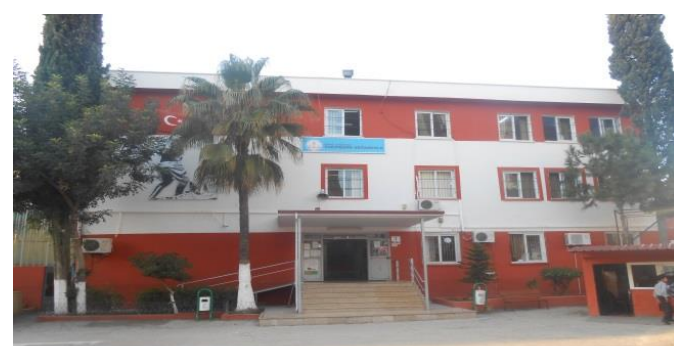

Şekil 2. Vakıfbank Ortaokulu ön cephe görünüşü 
Çizelge 1. Yap1 özellikleri ve analiz parametreleri

\begin{tabular}{|c|c|}
\hline Yapının Adı: & Sabancı İlkokulu \\
\hline Adresi: & Çukurova/Adana \\
\hline Yapım Yılı: & 1998 Öncesi \\
\hline Kat Adedi (N): & Zemin kat+2 Normal kat \\
\hline Kat Alanı $\left(\mathbf{m}^{2}\right)$ : & $\begin{array}{l}\text { Zemin Kat: } 680 \\
\text { 1. N. Kat: } 680 \\
\text { 2. N. Kat: } 680\end{array}$ \\
\hline Toplam Yapı Alanı: & $2040 \mathrm{~m}^{2}$ \\
\hline Yapının İmal Ediliş Tarzı: & Betonarme Karkas \\
\hline $\begin{array}{l}\text { Okul Yapılarının TDY- } \\
\text { 2007'ye Göre Sağlaması } \\
\text { Gereken Performans } \\
\text { Düzeyleri: }\end{array}$ & $\begin{array}{l}\text { 50 Yılda Așılma Olasılığı: } \\
* \% \text { 10 Hemen Kullanım } \\
\text { Koşulu } \\
* \% 2 \text { Can Güvenliği Koşulu }\end{array}$ \\
\hline Deprem Bölgesi: & 2. Derece Deprem Bölgesi \\
\hline $\begin{array}{l}\text { Etkin Yer İvmesi Katsayısı } \\
\left(A_{0}\right) \text { : }\end{array}$ & 0,30 \\
\hline $\begin{array}{l}\text { Taban Kesme Kuvveti } \\
\text { Katsayısı: }\end{array}$ & 0,85 \\
\hline $\begin{array}{l}\text { Hareketli Yük Katılım } \\
\text { Katsayısı: }\end{array}$ & 0,60 \\
\hline $\begin{array}{l}\text { Spektrum Karakteristik } \\
\text { Periyotları: }\end{array}$ & $\mathrm{T}_{\mathrm{A}}=0,15, \mathrm{~T}_{\mathrm{B}}=0,40$ \\
\hline Yerel Zemin Sinıfı: & $\mathrm{Z} 2$ \\
\hline $\begin{array}{l}\text { Sondaj Sonucu Elde } \\
\text { Edilen Zemin Emniyet } \\
\text { Gerilmesi Değeri }\left(\sigma_{z e m}\right) \text { : }\end{array}$ & $1,80 \mathrm{kgf} / \mathrm{cm}^{2}$ \\
\hline Mevcut Bina Bilgi Düzeyi: & Orta Bilgi Düzeyi \\
\hline $\begin{array}{l}\text { Mevcut Bina Bilgi Düzeyi } \\
\text { Katsayısı: }\end{array}$ & 0,90 \\
\hline $\begin{array}{l}\text { Mevcut Durum Beton } \\
\text { Dayanımı }\left(F_{\mathrm{ck}}\right) \text { : }\end{array}$ & 6,26 MPa \\
\hline $\begin{array}{l}\text { Beton Elastisite Modülü } \\
\text { Değeri: }\end{array}$ & $221315 \mathrm{~kg} / \mathrm{cm}^{2}$ \\
\hline Mevcut Asal Donatı Sınıfi: & St I - St III \\
\hline Mevcut Etriye Sinıfi: & St I (BÇI) \\
\hline $\begin{array}{l}\text { Taşıyıcı Elemanlarda } \\
\text { Donatı Gerçekleşme } \\
\text { Katsayısı: }\end{array}$ & $\begin{array}{l}\text { Yatayda: } 1,00 \\
\text { Düşeyde: } 0,75\end{array}$ \\
\hline $\begin{array}{l}\text { Mevcut Betonarme Perde } \\
\text { En Kesit Alanı / Kat Alanı } \\
\text { (Her İki Yön İçin) }\end{array}$ & $\begin{array}{l}\text { X-Yönü:0,00688 } \\
\text { Y-Yönü:0,00432 }\end{array}$ \\
\hline
\end{tabular}

\begin{tabular}{|c|c|}
\hline Düzeyleri: & *\% 2 Can Güvenliği Koşulu \\
\hline Deprem Bölgesi: & 2. Derece Deprem Bölgesi \\
\hline $\begin{array}{l}\text { Etkin Yer İvmesi Katsayısı } \\
\left(A_{0}\right):\end{array}$ & 0,30 \\
\hline $\begin{array}{l}\text { Taban Kesme Kuvveti } \\
\text { Katsayısı: }\end{array}$ & 0,85 \\
\hline $\begin{array}{l}\text { Hareketli Yük Katılım } \\
\text { Katsayısı: }\end{array}$ & 0,60 \\
\hline $\begin{array}{l}\text { Spektrum Karakteristik } \\
\text { Periyotları: }\end{array}$ & $\mathrm{T}_{\mathrm{A}}=0,15, \mathrm{~T}_{\mathrm{B}}=0,40$ \\
\hline Yerel Zemin Sınıf: & $\mathrm{Z} 2$ \\
\hline $\begin{array}{l}\text { Sondaj Sonucu Elde } \\
\text { Edilen Zemin Emniyet } \\
\text { Gerilmesi Değeri } \quad\left(\sigma_{\mathrm{zem}}\right):\end{array}$ & $2,00 \mathrm{kgf} / \mathrm{cm}^{2}$ \\
\hline Mevcut Bina Bilgi Düzeyi: & Orta Bilgi Düzeyi \\
\hline $\begin{array}{l}\text { Mevcut Bina Bilgi Düzeyi } \\
\text { Katsayısı: }\end{array}$ & 0,90 \\
\hline $\begin{array}{l}\text { Mevcut Durum Beton } \\
\text { Dayanımı }\left(F_{c k}\right) \text { : }\end{array}$ & 7,77 MPa \\
\hline $\begin{array}{l}\text { Beton Elastisite Modülü } \\
\text { Değeri: }\end{array}$ & $230,500 \mathrm{~kg} / \mathrm{cm}^{2}$ \\
\hline $\begin{array}{l}\text { Mevcut Asal Donatı ve } \\
\text { Etriye Sinıfi: }\end{array}$ & St I (BÇI) \\
\hline $\begin{array}{l}\text { Taşıyıcı Elemanlarda } \\
\text { Donatı Gerçekleşme } \\
\text { Katsayısı: } \\
\end{array}$ & $\begin{array}{l}\text { Yatayda: } 1,00 \\
\text { Düşeyde: } 1,00\end{array}$ \\
\hline $\begin{array}{l}\text { Mevcut Betonarme Perde } \\
\text { En Kesit Alanı / Kat Alanı } \\
\text { (Her İki Yön İçin) }\end{array}$ & $\begin{array}{l}\text { X-Yönü: } 0,0140 \\
\text { Y-Yönü: } 0,0094\end{array}$ \\
\hline
\end{tabular}

\section{MATERYAL VE METOT}

İncelenen okul yapılarının deprem tahkiki çalışmaları, Türk Deprem Yönetmeliğinde "Mevcut Binaların Değerlendirilmesi ve Güçlendirilmesi" bölümünde yer alan "Doğrusal Elastik Hesap Yöntemleri” esasları çerçevesinde sırasıyla, kısaca aşağıda verilen adımlar takip edilerek gerçekleştirilmiştir. [8]

\section{İzlenen adımlar:}

Çizelge 2. Yap1 özellikleri ve analiz parametreleri

\begin{tabular}{|c|c|}
\hline Yapının Adı: & Vakıfbank Ortaokulu \\
\hline Adresi: & Çukurova/Adana \\
\hline Yapım Yılı: & 1998 Öncesi \\
\hline Kat Adedi (N): & Zemin kat+2 Normal kat \\
\hline Kat Alanı $\left(\mathbf{m}^{2}\right)$ : & $\begin{array}{l}\text { Zemin Kat: } 321,93 \\
\text { 1. N. Kat: } 321,93 \\
\text { 2. N. Kat: } 321,93\end{array}$ \\
\hline Toplam Yapı Alanı: & $965,79 \mathrm{~m}^{2}$ \\
\hline Yapının İmal Ediliş Tarzı: & Betonarme Karkas \\
\hline $\begin{array}{l}\text { Okul Yapılarının TDY- } \\
\text { 2007'ye Göre Sağlaması } \\
\text { Gereken Performans }\end{array}$ & $\begin{array}{l}50 \text { Yılda Aşılma Olasılığı: } \\
\text { *\% } 10 \text { Hemen Kullanım } \\
\text { Koşulu }\end{array}$ \\
\hline
\end{tabular}

Binanın Mevcut Durumunun Saptanmasi:

Röleve çalışmaları

> Yapının mimari rölevesinin hazırlanması

$>$ Yapının taşıyıcı sistem rölevesinin hazırlanması

Mevcut Malzeme Kalitesinin Belirlenmesi:

Beton Dayanımının Belirlenmesi

$>$ Donatı Sınıfi, Düzeni ve Miktarının Belirlenmesi 
* Temel Sisteminin Belirlenmesi:

Muayene çukurları açılması

* Binanın Oturduğu Zemin Özelliklerinin Belirlenmesi:

Sondaj çalışmalarının yapılması

* Yapıdan Bilgi Elde Edilmesi İşlemlerinin Sonucunda Oluşan Tahribatların Giderilmesi

Siyırma yapılan yerlerin siva ile onarılması

$>$ Beton numune alınan yerlerin özel tamir harc1 (hacim alan, şişen) ile doldurularak kapatılmas

$>$ Temelde ve zeminde oluşan muayene/ sondaj çukurlarının kapatılması

* Elde Edilen Veriler Işığında Yapının 3 Boyutlu Modelinin Oluşturulması:

* İncelenen Okul Binaları İçin Yapı Performans Analizlerinin Gerçekleştirilmesi:

> Hemen kullanım koşulu

$>$ Can güvenliği koşulu

* Performans Durumu İncelenerek Risk Değerlendirmesi Yapılması [9].

Performans Yetersizliği Durumunda Yap1 Güçlendirme Projesinin Hazırlanması

* Maliyet Analizi Sonucunda Güçlendirme veya Yeni Baştan Yapım Kararının Alınması

\subsection{Yapı Beton Dayanımının Belirlenmesi}

Yapıda kullanılmış olan mevcut beton kalitesinin bulunması amacıyla, binanın çeşitli yerlerindeki taşıyıcı sistem elemanlarından alınan beton numuneler basınç dayanımı testine tabi tutulmuş ve kullanılan beton sınıfi belirlenmiştir. $\mathrm{Bu}$ dayanım belirlenen standart sapma neticesinde ortalama bir değeri yansıtmaktadır.

2007 Deprem Yönetmeliğine göre “Orta Bilgi Düzeyinde" bilgi toplanırken binadan alınması gereken minimum beton numune sayısı aşağıda verilen şartlara göre belirlenmektedir [8].

$\checkmark$ Her kattaki kolon veya perdelerden toplam 3 adetten az olmayacak,

$\checkmark$ Binada toplam 9 adetten az olmayacak,

$\checkmark$ Toplam alınan numune her $400 \mathrm{~m}^{2}$ 'de 1 adetten az olmayacak şekilde beton numune alımı gerçekleştirilmiştir.

Çizelge 3. Beton numune değerleri

\begin{tabular}{|l|c|c|}
\hline Yapının Adı: & $\begin{array}{l}\text { Vakıfbank } \\
\text { Ortaokulu }\end{array}$ & $\begin{array}{l}\text { Sabancı } \\
\text { İlkokulu }\end{array}$ \\
\hline Kat Alanı $\left(\mathrm{m}^{2}\right):$ & 322 & 680 \\
\hline $\begin{array}{l}\text { Her Katta Alınan } \\
\text { Beton Numune }\end{array}$ & 9 adet & 9 adet \\
\hline $\begin{array}{l}\text { Ortalama Beton } \\
\text { Dayanımı (MPa) }\end{array}$ & 7,77 & 6,26 \\
\hline
\end{tabular}
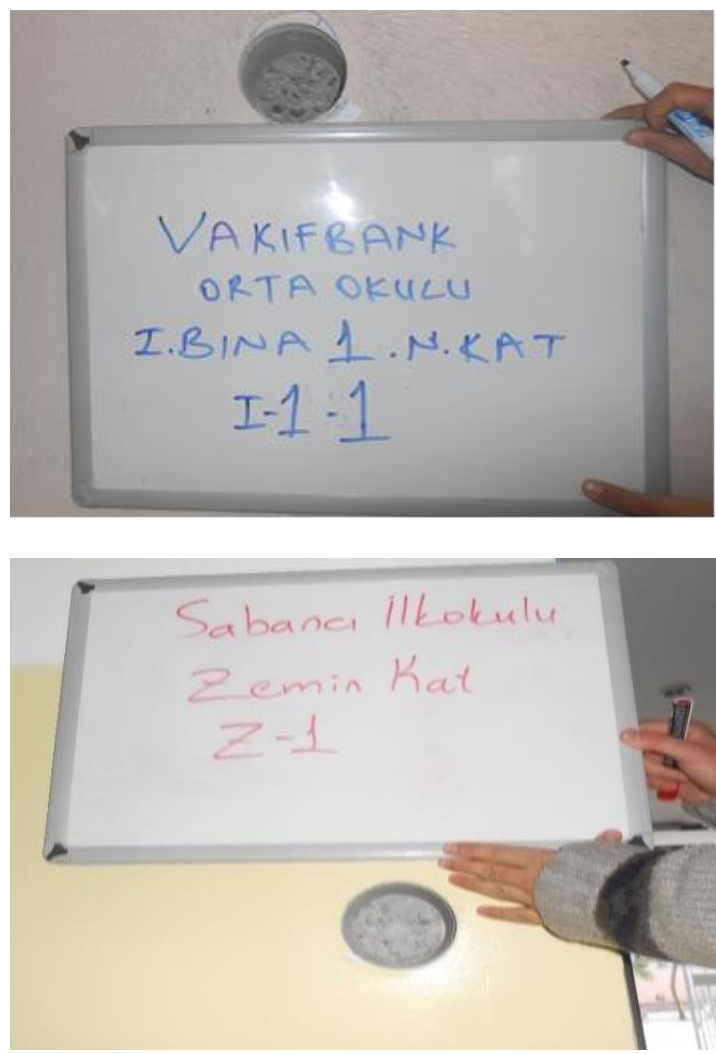

Şekil 3. Yapıdan beton numune alınması işlemleri

Bahsi geçen yapılara ait mimari planlar Şekil 4 ve Şekil 5 'te, taşıyıcı sistem röleve planları ise Şekil 6 ve Şekil 7'de verilmiştir. 


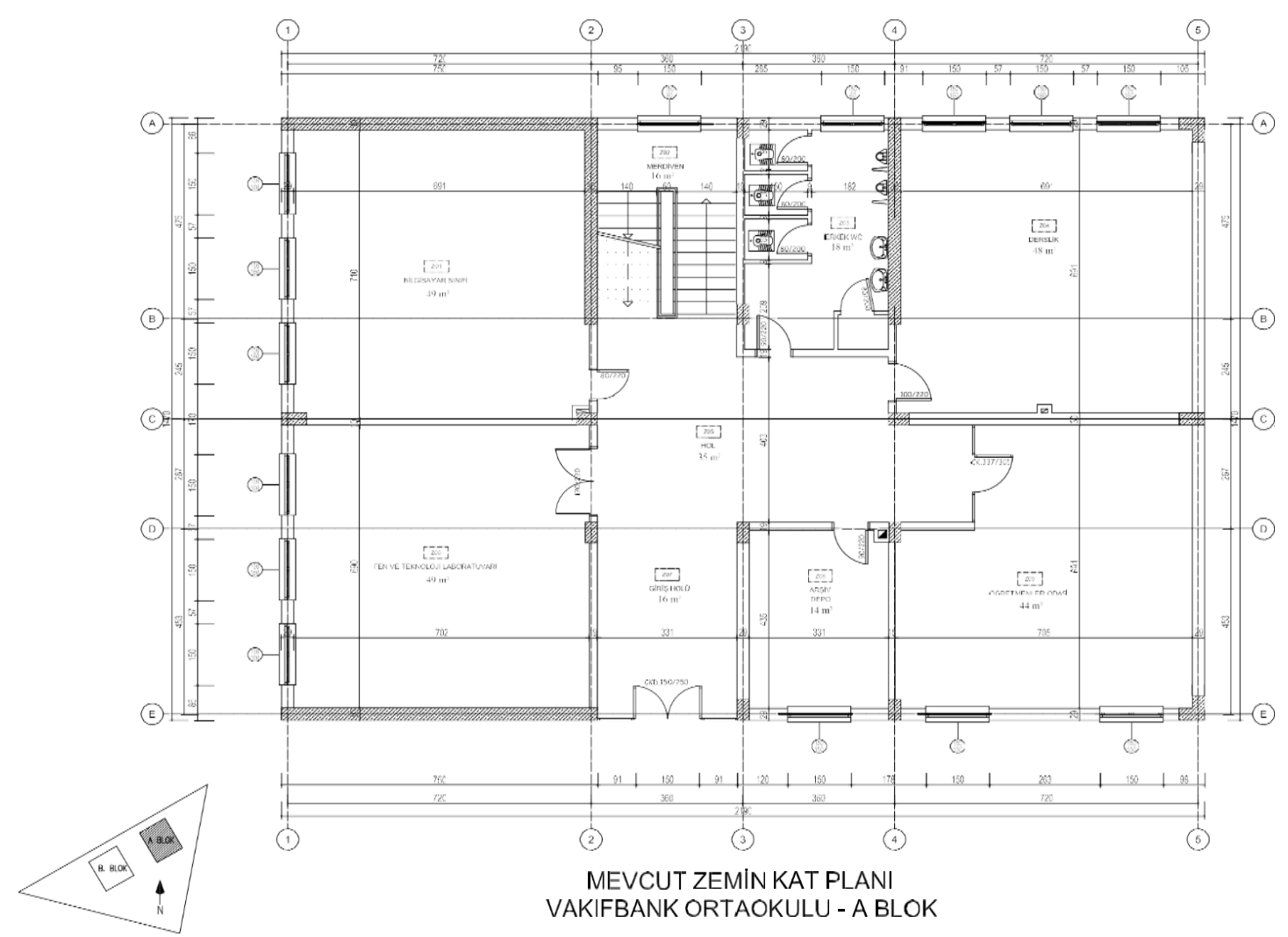

Şekil 4. Vakıfbank Ortaokulu kat mimari planı

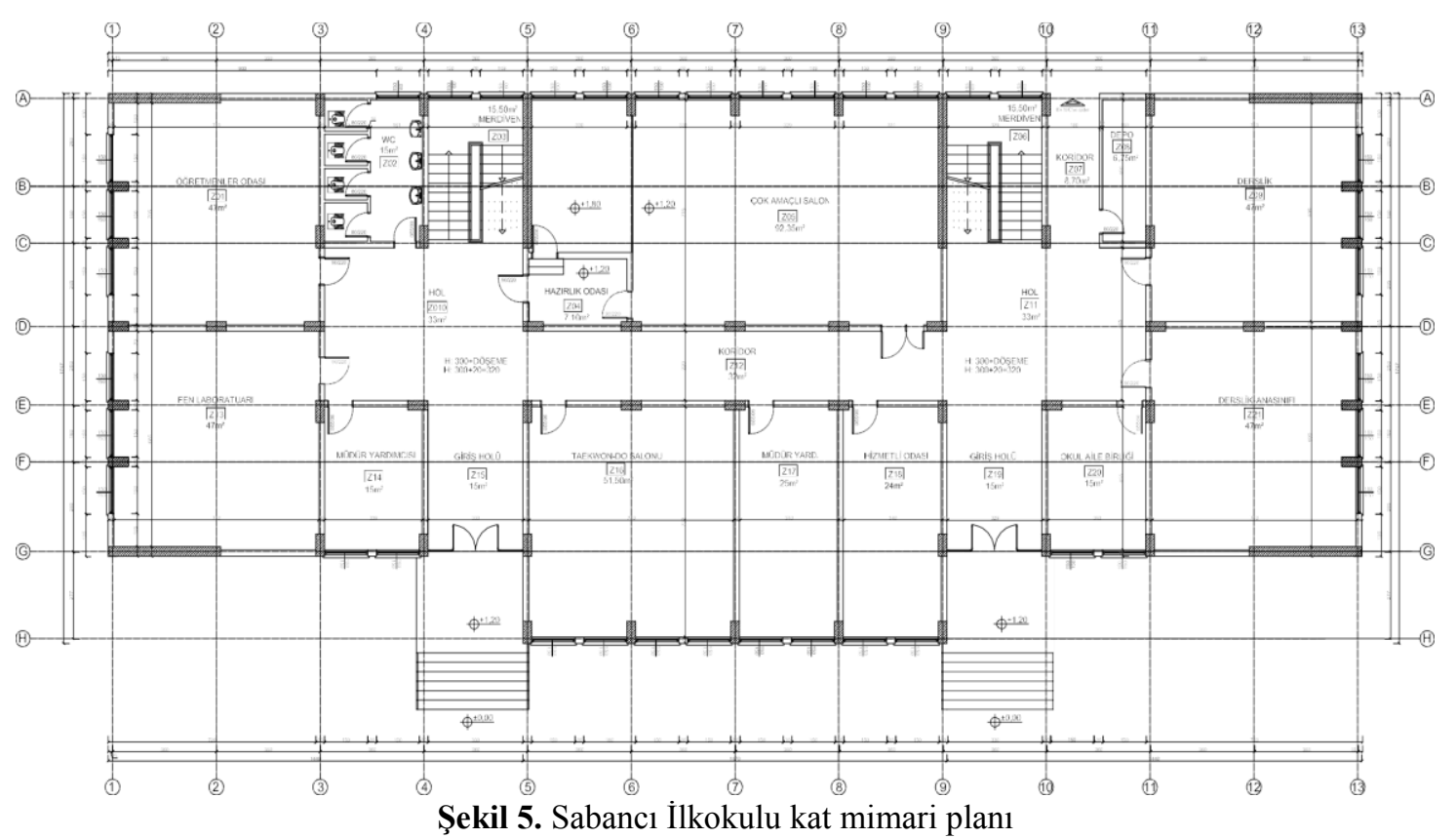




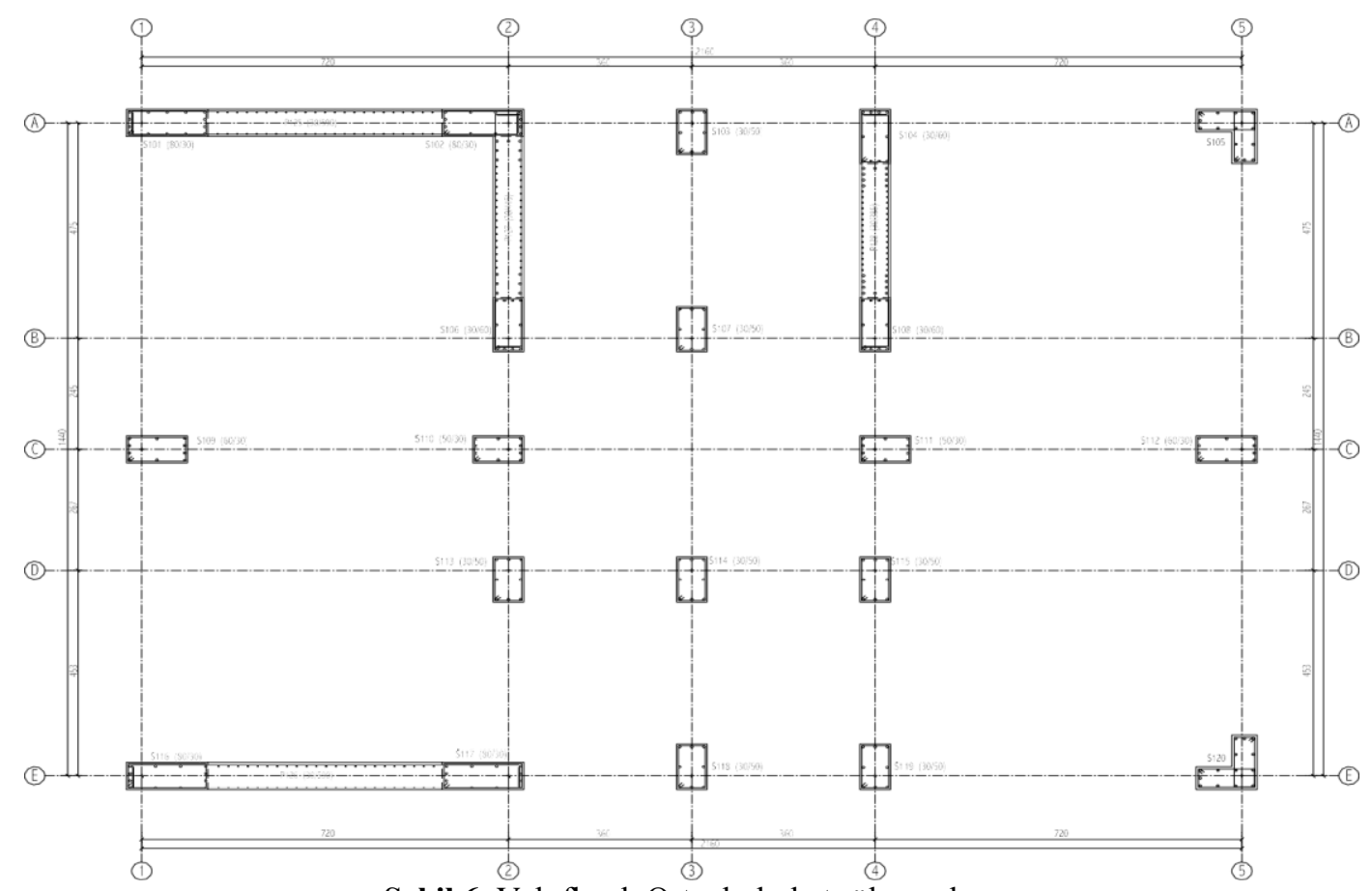

Şekil 6. Vakıfbank Ortaokulu kat röleve planı

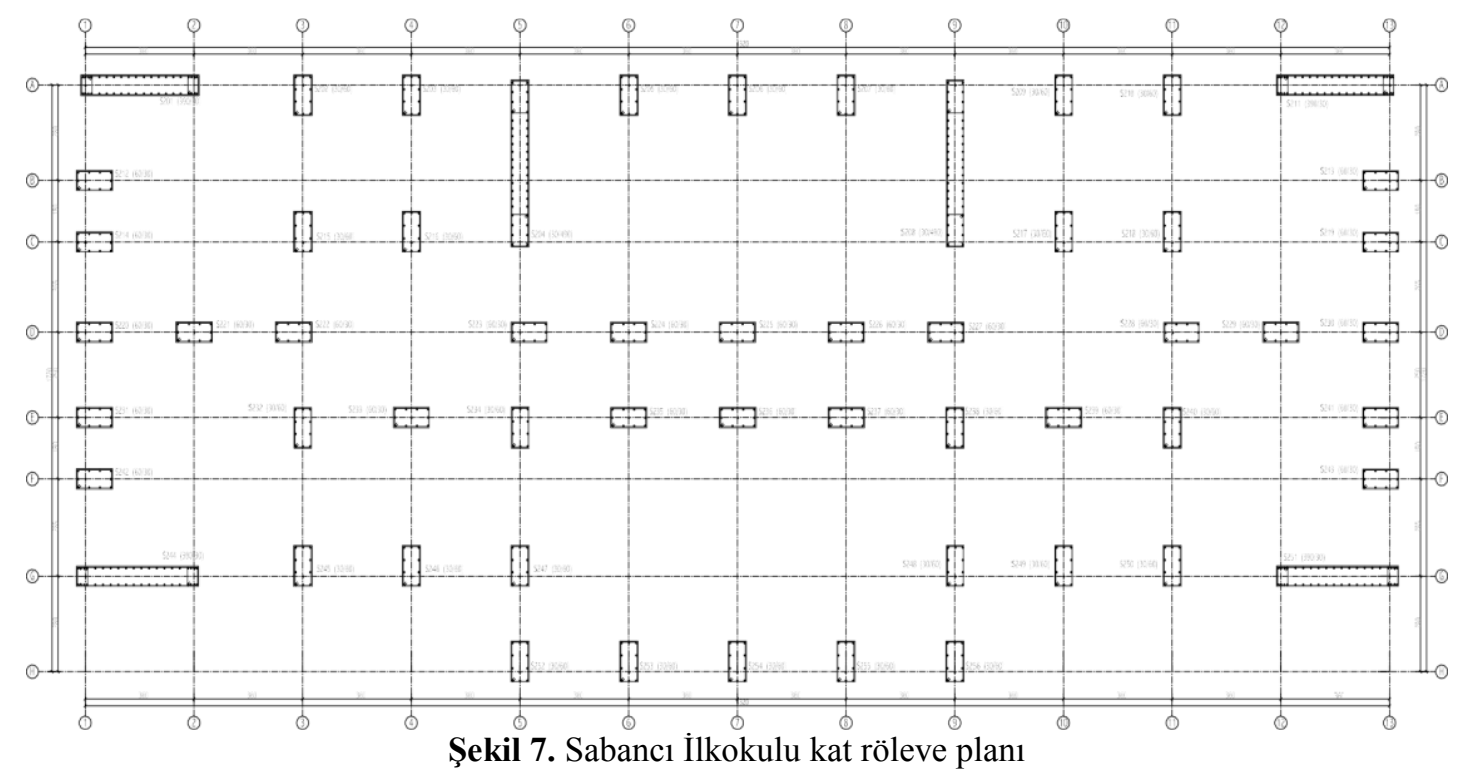

\subsection{Donatı Miktarı ve Sınıfının Belirlenmesi}

Donatı kalite ve düzeninin belirlenebilmesi amacıyla binanın bazı kolon, perde ve kirişlerinde beton örtüsü sıyırma işlemi yapılmıştır. Ayrıca cihaz vasitası ile hasarsız donatı taraması gerçekleştirilmiştir. Her iki yapıda belirlenen donatı sınıfları Çizelge 1 ve Çizelge 2' de verilmiştir. 


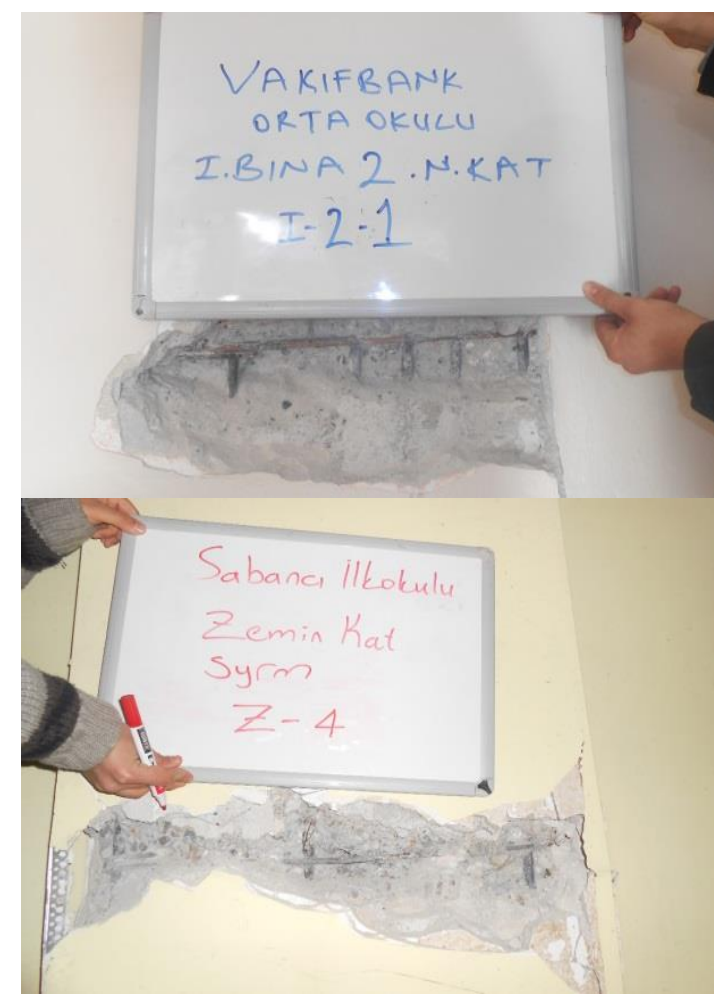

Şekil 8. Donatı tespitinin yapılması işlemleri

Betonarme taşıyıcı elemanlar üzerinde yapılan sıyırma ve tarama işlemleri ile elde edilen verilerin sonucunda; taşıyıcı sistemde bulunan mevcut donatı miktarının, yapının yapıldığı yıl geçerli olan yönetmeliğin gerektirdiği minimum donat1 miktarına oranıyla ortaya çıkan "Donatı Gerçekleşme Katsayısı" belirlenmiştir. Bu değer donatı tespiti yapılmayan diğer tüm elemanlara uygulanarak mevcut durumdaki olası donatı miktarları belirlenir.

Bir tahmin durumu söz konusu olduğu için yönetmelikte de belirtildiği üzere hesaplamalarda kullanılan bu katsayı güvenli tarafta kalmak adına maksimum $1(\% 100)$ değerini alabilir. Katsayının 1 değerini alması binanın yapıldığı yıl geçerli olan yönetmelik koşullarına göre elemanlarda olması gereken minimum donatı miktarının mevcut durumda sağlanmış olduğu anlamına gelmektedir.

Yapılan incelemeler sonucunda Vakıfbank Ortaokulu için düşey taşıyıcı elemanlarda donatı gerçekleşme katsayısı 1,07, yatay taşıyıcı elemanlarda ise 1,22 olarak belirlense de yönetmelik gereği bu değerler hesaplamalarda "1,00" olarak alınacaktır. Sabancı İlkokulu için düşey taşıyıcı elemanlarda donatı gerçekleşme katsayıs1 0,75, yatay taşıyıcı elemanlarda ise 1,00 olarak belirlenmiştir.

\section{BULGULAR VE TARTIŞMA}

Yapıların bilgisayar ortamında üç boyutlu olarak modellenmesinden sonra, yapı kullanım amacı ve türüne göre belirlenen farklı büyüklükteki deprem etkileri altında, binaların performans analizleri gerçekleştirilmiştir. Yapı kullanım amacı ve türüne bağlı olarak okullardan beklenen performans düzeyleri Çizelge 4'te verildiği gibidir.

Çizelge 4. Bina minimum performans koşulları

\begin{tabular}{|c|c|c|c|}
\hline \multirow{2}{*}{$\begin{array}{l}\text { Binanın Kullanım } \\
\text { Amacı ve Türü }\end{array}$} & \multicolumn{3}{|c|}{$\begin{array}{c}\text { Depremin Aşıılma } \\
\text { Olasılığı }\end{array}$} \\
\hline & $\begin{array}{c}50 \text { yılda } \\
\% 50\end{array}$ & $\begin{array}{c}50 \text { yilda } \\
\% 10\end{array}$ & $\begin{array}{c}50 \text { y1lda } \\
\% 2\end{array}$ \\
\hline $\begin{array}{l}\text { İnsanların Uzun } \\
\text { Süreli ve Yoğun } \\
\text { Olarak Bulunduğu } \\
\text { Binalar: } \\
\text { - Okullar, } \\
\text { - Yatakhaneler, } \\
\text { - Yurtlar/Pansiyonlar, } \\
\text { - Askeri Kişlalar } \\
\text { - Cezaevleri/Müzeler }\end{array}$ & - & HK & CG \\
\hline
\end{tabular}

Çizelgenin incelenmesinden de görüleceği üzere, bu çalışmada ele alınan binaların, 50 yılda aşılma olasılığ $\% 10$ olan bir deprem (orta ölçekli) için "Hemen Kullanım" performans düzeyini ve 50 yılda aşılma olasılığı \%2 olan bir deprem (büyük ölçekli) için "Can Güvenliğ̈i" performans düzeylerini sağlaması gerekmektedir [10].

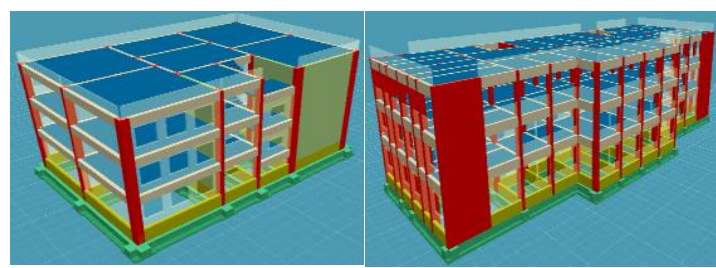

Şekil 9. Mevcut yap1 modelleri 


\subsection{Orta Ölçekli Bir Deprem Etkisi Altında Binalarm Performans Analizinin Yapilması}

Öncelikle, orta ölçekli bir deprem etkisinde binaların performans analizi yapılmıştır. $\mathrm{Bu}$ amaçla $\mathrm{x}$ - ve $\mathrm{y}$ - doğrultularında deprem analizleri, "Bina önem katsayıss" ve "Deprem yükü azaltma katsayısı" değerleri değiștirilmeden $\left(I=1, R_{a}=1\right)$ gerçekleștirilmiştir. Yapılan performans analizleri sonucunda 50 yılda aşılma olasıllığ $\% 10$ olan orta ölçekli muhtemel bir deprem etkisi altında, binaya ait kiriş ve kolonlarda meydana gelen hasar yüzdeleri Vakıfbank Ortaokulu için Çizelge 5 ve Çizelge 6'da ve Sabancı İlkokulu için Çizelge 7 ve Çizelge 8'de belirtildiği gibidir.

Türk Deprem Yönetmeliğine göre herhangi bir katta, her bir deprem doğrultusu için yapılan hesap sonucunda Hemen Kullanım Performans Düzeyinin sağlanabilmesi için gerekli olan koşullar şunlardır:

$\checkmark$ Kirişlerin \%10’u Belirgin Hasar Bölgesine geçebilir.

$\checkmark$ Diğer taşıyıcı elemanların tümü Minimum Hasar Bölgesinde olacaktır.

$\checkmark$ Eğer gevrek olarak hasar gören elemanlar varsa bu elemanların güçlendirilmesi şartı ile söz konusu incelenen binanın Hemen Kullanım Performans Düzeyinde olduğu kabul edilir.

Her iki bina için de elde edilen veriler, bu yapıların orta ölçekli bir deprem etkisinde "Hemen Kullanım” performans düzeyini sağlayamadığını göstermektedir.

\subsection{Büyük Ölçekli Bir Deprem Etkisi Altında Binaların Performans Analizleri}

İncelenmekte olan yapılar insanların uzun süreli ve yoğun olarak bulunduğu binalar sınıfina girdiği için orta ölçekli bir deprem etkisinin yanı sıra, büyük ölçekli bir deprem etkisinde de performans analizleri yapılmıştır. Bu amaçla binanın $\mathrm{x}$ - ve $\mathrm{y}$ doğrultularında, her iki yönde deprem analizleri, "Bina önem katsayısı" ve "Deprem yükü azaltma katsayısı" için sirasıyla $I=1,5$ ve $R_{a}=1$ değerleri kullanılarak yapılmıştır [11].
Türk Deprem Yönetmeliğine göre varsa gevrek olarak hasar gören elemanların onarılması ve güçlendirilmesi şartı ile aşağıda verilmiş olan koşulları sağlayan yapıların Can Güvenliği Performans Düzeyinde olduğu kabul edilmektedir. Bunun için gerekli olan koşullar şunlardır:

Binada herhangi bir katta, sisteme uygulanan bütün deprem doğrultuları için yapılan hesap sonucunda, yatay yük taşıyıcı sisteminde yer almayan (ikincil) kirişler hariç olmak üzere; kirişlerin en fazla $\% 30$ 'u, kolonların ise bir sonraki takip eden koşulda tanımlandığı kadarı İleri Hasar Bölgesine geçebilir.

$\checkmark$ İleri Hasar Bölgesinde bulunan kolonların, her bir katta kolonlar tarafından taşınan kesme kuvvetine toplamda yapmış oldukları katkı $\% 20$ 'nin altında olmalıdır. En üst katta ise bu katta bulunan ve İleri Hasar durumunda olan kolonların kesme kuvvetleri toplamının, söz konusu kattaki tüm kolonların kesme kuvvetlerinin toplamına oranı en çok $\% 40$ olabilir.

$\checkmark$ Diğer taşıyıcı elemanların tümü Minimum Hasar bölgesi veya Belirgin Hasar bölgesindedir. Ancak, herhangi bir katta alt ve üst kesitlerinin ikisinde birden Minimum Hasar Sınırı aşılmış olan kolonlar tarafından taşınan kesme kuvvetlerinin, o kattaki tüm kolonlar tarafindan taşınan kesme kuvvetine oranının \% 30'u aşmaması gerekir.

Deprem yönetmeliğinde kolonların kirişlerden daha güçlü olması koşulunun sağlanabilesi için: her bir kolon-kiriş düğüm noktasına birleșen kolonların alt ve üst ucundaki taşıma gücü momentlerinin toplamı, o düğüm noktasına birleşen kirişlerin kolon yüzündeki kesitlerindeki taşıma gücü momentleri toplamından $\% 20$ daha büyük olmalıdır.

Yapılan performans analizleri sonucunda 50 yılda aşılma olasılığ $1 \% 2$ olan büyük ölçekli muhtemel bir deprem etkisi altında, binaya ait kiriş ve kolonlarda meydana gelen hasar yüzdeleri Vakıfbank Ortaokulu için Çizelge 9 ve 
Çizelge 10'da Sabancı İlkokulu için ise Çizelge 11 ve Çizelge 12 'de belirtildiği gibidir.

Her iki bina için de elde edilen veriler, bu yapıların büyük ölçekli bir deprem etkisinde "Can
Güvenliğgi" performans düzeyini sağlayamadı̆̆ 1 , dolayısı ile deprem etkisi altında riskli bina sınıfına girdiği anlaşılmaktadır [12].

Çizelge 5. Vakıfbank Ortaokulu için kiriş hasar yüzdeleri (Orta ölçekli deprem)

\begin{tabular}{|c|c|c|c|c|c|c|c|c|c|c|c|c|c|c|c|c|}
\hline $\begin{array}{c}\text { KAT } \\
\text { NO }\end{array}$ & $\mathbf{9 H}$ & $\mathbf{B H}$ & $\mathbf{I H}$ & $\mathbf{G B}$ & $\mathbf{M H}$ & $\mathbf{B H}$ & $\mathbf{I H}$ & $\mathbf{G B}$ & $\mathbf{M H}$ & $\mathbf{B H}$ & $\mathbf{I H}$ & $\mathbf{G B}$ & $\mathbf{M H}$ & $\mathbf{B H}$ & $\mathbf{I H}$ & $\mathbf{G B}$ \\
\hline $\mathbf{3}$ & 100, & 0,0 & 0,0 & 0,0 & 100, & 0,0 & 0,0 & 0,0 & 100, & 0,0 & 0,0 & 0,0 & 90,9 & 9,1 & 0,0 & 0,0 \\
\hline $\mathbf{2}$ & 100, & 0,0 & 0,0 & 0,0 & 100, & 0,0 & 0,0 & 0,0 & 91,7 & 8,3 & 0,0 & 0,0 & 91,7 & 8,3 & 0,0 & 0,0 \\
\hline $\mathbf{1}$ & 100, & 0,0 & 0,0 & 0,0 & 100, & 0,0 & 0,0 & 0,0 & 100, & 0,0 & 0,0 & 0,0 & 100, & 0,0 & 0,0 & 0,0 \\
\hline Max. & 100, & & & & & & & & & & & & & 9,1 & & \\
\hline
\end{tabular}

*MH: Minimum Hasar, BH: Belirgin Hasar

Çizelge 6. Vakıfbank Ortaokulu için kolon hasar yüzdeleri (Orta ölçekli deprem)

\begin{tabular}{|c|c|c|c|c|c|c|c|c|c|c|c|c|c|c|c|c|}
\hline \multirow{2}{*}{$\begin{array}{c}\text { KAT } \\
\text { NO }\end{array}$} & \multicolumn{4}{|c|}{$\mathbf{( - X )}$} & \multicolumn{5}{|c|}{$\mathbf{( + X )}$} & \multicolumn{4}{|c|}{$(\mathbf{- Y )}$} & \multicolumn{4}{|c|}{$\mathbf{( + Y )}$} \\
\hline & $\mathbf{M H}$ & $\mathbf{B H}$ & $\mathbf{I H}$ & $\mathbf{G B}$ & $\mathbf{M H}$ & $\mathbf{B H}$ & $\mathbf{I H}$ & $\mathbf{G B}$ & $\mathbf{M H}$ & $\mathbf{B H}$ & $\mathbf{I H}$ & $\mathbf{G B}$ & $\mathbf{M H}$ & $\mathbf{B H}$ & $\mathbf{I H}$ & $\mathbf{G B}$ \\
\hline $\mathbf{3}$ & 99,7 & 0,0 & 0,1 & 0,1 & 99,7 & 0,0 & 0,0 & 0,3 & 99,6 & 0,4 & 0,0 & 0,0 & 99,7 & 0,0 & 0,3 & 0,0 \\
\hline $\mathbf{2}$ & 99,9 & 0,0 & 0,0 & 0,1 & 99,9 & 0,0 & 0,0 & 0,1 & 100, & 0,0 & 0,0 & 0,0 & 100, & 0,0 & 0,0 & 0,0 \\
\hline $\mathbf{1}$ & 100, & 0,0 & 0,0 & 0,0 & 100, & 0,0 & 0,0 & 0,0 & 99,1 & 0,0 & 0,0 & 0,9 & 99,1 & 0,0 & 0,0 & 0,9 \\
\hline Max. & & & & & & & & & 100, & 0,4 & & & & & 0,3 & 0,9 \\
\hline
\end{tabular}

*IH: İleri Hasar, GB: Göçme Bölgesi

Çizelge 7. Sabancı İlkokulu için kiriş hasar yüzdeleri (Orta ölçekli deprem)

\begin{tabular}{|c|c|c|c|c|c|c|c|c|c|c|c|c|c|c|c|c|}
\hline $\begin{array}{c}\text { KAT } \\
\text { NO }\end{array}$ & $\mathbf{9 H}$ & $\mathbf{B H}$ & $\mathbf{I H}$ & $\mathbf{G B}$ & $\mathbf{M H}$ & $\mathbf{B H}$ & $\mathbf{I H}$ & $\mathbf{G B}$ & $\mathbf{M H}$ & $\mathbf{B H}$ & $\mathbf{I H}$ & $\mathbf{G B}$ & $\mathbf{M H}$ & $\mathbf{B H}$ & $\mathbf{I H}$ & $\mathbf{G B}$ \\
\hline $\mathbf{3}$ & 100, & 0,0 & 0,0 & 0,0 & 96,0 & 0,0 & 4,0 & 0,0 & 100, & 0,0 & 0,0 & 0,0 & 95,1 & 0,0 & 0,0 & 4,9 \\
\hline $\mathbf{2}$ & 78,0 & 22,0 & 0,0 & 0,0 & 84,0 & 12,0 & 4,0 & 0,0 & 75,6 & 24,4 & 0,0 & 0,0 & 70,7 & 17,1 & 0,0 & 12,2 \\
\hline $\mathbf{1}$ & 91,7 & 8,3 & 0,0 & 0,0 & 89,6 & 29,2 & 4,2 & 0,0 & 75,6 & 22,0 & 0,0 & 2,4 & 73,2 & 19,5 & 2,4 & 4,9 \\
\hline Max. & 100, & & & & & & 4,2 & & & 24,4 & & & & & & 12,2 \\
\hline
\end{tabular}

Çizelge 8. Sabancı İlkokulu için kolon hasar yüzdeleri (Orta ölçekli deprem)

\begin{tabular}{|c|c|c|c|c|c|c|c|c|c|c|c|c|c|c|c|c|}
\hline \multirow{2}{*}{$\begin{array}{c}\text { KAT } \\
\text { NO }\end{array}$} & \multicolumn{4}{|c|}{$(-X)$} & \multicolumn{4}{|c|}{$(+X)$} & \multicolumn{4}{|c|}{$(-Y)$} & \multicolumn{4}{|c|}{$(+\mathrm{Y})$} \\
\hline & MH & BH & IH & GB & MH & BH & IH & GB & MH & BH & IH & GB & MH & BH & IH & GB \\
\hline 3 & 51,1 & 45,9 & 1,4 & 1,7 & 52,7 & 44,3 & 1,4 & 1,7 & 72,0 & 26,4 & 0,0 & 1,6 & 68,6 & 24,8 & 5,0 & 1,5 \\
\hline 2 & 30,8 & 69,2 & 0,0 & 0,0 & 31,1 & 68,9 & 0,0 & 0,0 & 38,7 & 59,8 & 0,0 & 1,5 & 40,5 & 57,4 & 0,5 & 1,6 \\
\hline 1 & 65,7 & 0,0 & 0,0 & 34,3 & 65,7 & 0,0 & 0,0 & 34,3 & 67,0 & 0,6 & 0,0 & 32,4 & 70,2 & 0,6 & 0,0 & 29,2 \\
\hline Max. & & 69,2 & & 34,3 & & & & & 72,0 & & & & & & 5,0 & \\
\hline
\end{tabular}

Çizelge 9. Vakıfbank Ortaokulu için kiriş hasar yüzdeleri (Büyük ölçekli deprem)

\begin{tabular}{|c|c|c|c|c|c|c|c|c|c|c|c|c|c|c|c|c|}
\hline \multirow{2}{*}{$\begin{array}{c}\text { KAT } \\
\text { NO }\end{array}$} & $\mathbf{M H}$ & $\mathbf{B H}$ & $\mathbf{I H}$ & $\mathbf{G B}$ & $\mathbf{M H}$ & $\mathbf{B H}$ & $\mathbf{I H}$ & $\mathbf{G B}$ & $\mathbf{M H}$ & $\mathbf{B H}$ & $\mathbf{I H}$ & $\mathbf{G B}$ & $\mathbf{M H}$ & $\mathbf{B H}$ & $\mathbf{I H}$ & $\mathbf{G B}$ \\
\hline $\mathbf{3}$ & 100, & 0,0 & 0,0 & 0,0 & 100, & 0,0 & 0,0 & 0,0 & 72,7 & 27,3 & 0,0 & 0,0 & 81,8 & 9,1 & 9,1 & 0,0 \\
\hline $\mathbf{2}$ & 100, & 0,0 & 0,0 & 0,0 & 100, & 0,0 & 0,0 & 0,0 & 83,3 & 16,7 & 0,0 & 0,0 & 83,3 & 8,3 & 8,3 & 0,0 \\
\hline $\mathbf{1}$ & 100, & 0,0 & 0,0 & 0,0 & 100, & 0,0 & 0,0 & 0,0 & 75,0 & 25,0 & 0,0 & 0,0 & 83,3 & 16,7 & 0,0 & 0,0 \\
\hline Max. & 100, & & & & & & & & & 27,3 & & & & & 9,1 & \\
\hline
\end{tabular}


Çizelge10. Vakıfbank Ortaokulu için kolon hasar yüzdeleri (Büyük ölçekli deprem)

\begin{tabular}{|c|c|c|c|c|c|c|c|c|c|c|c|c|c|c|c|c|}
\hline \multirow{2}{*}{$\begin{array}{c}\text { KAT } \\
\text { NO }\end{array}$} & \multicolumn{4}{|c|}{$(-X)$} & \multicolumn{4}{|c|}{$(+X)$} & \multicolumn{4}{|c|}{$(-Y)$} & \multicolumn{4}{|c|}{$(+Y)$} \\
\hline & MH & BH & IH & GB & MH & $\mathbf{B H}$ & IH & GB & MH & BH & IH & GB & MH & BH & IH & GB \\
\hline 3 & 99,7 & 0,0 & 0,0 & 0,3 & 99,7 & 0,0 & 0,0 & 0,3 & 97,9 & \begin{tabular}{|l|}
1,7 \\
\end{tabular} & 0,4 & 0,0 & 98,9 & 0,7 & 0,0 & 0,3 \\
\hline 2 & 99,7 & 0,2 & 0,0 & 0,1 & 99,9 & 0,0 & 0,0 & 0,1 & 94,9 & 5,1 & 0,0 & 0,0 & 96,5 & 3,5 & 0,0 & 0,0 \\
\hline 1 & 99,8 & 0,0 & 0,0 & 0,2 & 99,8 & 0,0 & 0,0 & 0,2 & 15,5 & 83,6 & 0,0 & 0,9 & 15,9 & 83,2 & 0,0 & 0,9 \\
\hline Max. & & & & & 99,9 & & & & & 83,6 & 0,4 & & & & & 0,9 \\
\hline
\end{tabular}

Çizelge 11. Sabancı İlkokulu için kiriş hasar yüzdeleri (Büyük ölçekli deprem)

\begin{tabular}{|c|c|c|c|c|c|c|c|c|c|c|c|c|c|c|c|c|}
\hline $\begin{array}{c}\text { KAT } \\
\text { NO }\end{array}$ & $\mathbf{M H}$ & $\mathbf{B H}$ & $\mathbf{I H}$ & $\mathbf{G B}$ & $\mathbf{M H}$ & $\mathbf{B H}$ & $\mathbf{I H}$ & $\mathbf{G B}$ & $\mathbf{M H}$ & $\mathbf{B H}$ & $\mathbf{I H}$ & $\mathbf{G B}$ & $\mathbf{M H}$ & $\mathbf{B H}$ & $\mathbf{I H}$ & $\mathbf{G B}$ \\
\hline $\mathbf{3}$ & 80,0 & 20,0 & 0,0 & 0,0 & 90,0 & 6,0 & 0,0 & 4,0 & 78,0 & 22,0 & 0,0 & 0,0 & 75,6 & 19,5 & 0,0 & 4,9 \\
\hline $\mathbf{2}$ & 38,0 & 48,0 & 14,0 & 0,0 & 38,0 & 48,0 & 10,0 & 4,0 & 36,6 & 34,1 & 22,0 & 7,3 & 36,6 & 36,6 & 14,6 & 12,2 \\
\hline $\mathbf{1}$ & 54,2 & 41,7 & 4,2 & 0,0 & 60,4 & 29,2 & 6,3 & 4,2 & 36,6 & 39,0 & 22,0 & 2,4 & 36,6 & 36,6 & 19,5 & 7,3 \\
\hline Max. & & 48,0 & & & 90,0 & & & & & & 22,0 & & & & & 12,2 \\
\hline
\end{tabular}

Çizelge 12. Sabancı İlkokulu için kolon hasar yüzdeleri (Büyük ölçekli deprem)

\begin{tabular}{|c|c|c|c|c|c|c|c|c|c|c|c|c|c|c|c|c|}
\hline $\begin{array}{c}\text { KAT } \\
\text { NO }\end{array}$ & $\mathbf{M H}$ & $\mathbf{B H}$ & $\mathbf{I H}$ & $\mathbf{G B}$ & $\mathbf{M H}$ & $\mathbf{B H}$ & $\mathbf{I H}$ & $\mathbf{G B}$ & $\mathbf{M H}$ & $\mathbf{B H}$ & $\mathbf{I H}$ & $\mathbf{G B}$ & $\mathbf{M H}$ & $\mathbf{B H}$ & $\mathbf{I H}$ & $\mathbf{G B}$ \\
\hline $\mathbf{3}$ & 33,0 & 58,4 & 5,5 & 3,1 & 32,9 & 58,5 & 5,5 & 3,1 & 52,9 & 33,5 & 7,0 & 6,5 & 48,0 & 34,5 & 8,3 & 9,2 \\
\hline $\mathbf{2}$ & 4,9 & 93,5 & 1,6 & 0,0 & 6,4 & 92,0 & 1,6 & 0,0 & 15,5 & 40,9 & 42,1 & 1,5 & 13,4 & 44,3 & 40,2 & 2,1 \\
\hline $\mathbf{1}$ & 52,1 & 13,7 & 0,0 & 34,3 & 52,1 & 13,6 & 0,0 & 34,3 & 26,8 & 40,8 & 0,0 & 32,4 & 29,2 & 41,6 & 0,0 & 29,2 \\
\hline Max. & & 93,5 & & 34,3 & & & & & 52,9 & & 42,1 & & & & & \\
\hline
\end{tabular}

\subsection{Yapıların Güçlendirilmesi Çalışmaları}

Çalışmada incelenen okul yapılarının güçlendirilmesinde takip edilen işlem adımları sırasıyla aşağıda verilmiştir. Bunlar:

* Yapılacak güçlendirme işleminin bilgisayar modeli üzerine işlenmesi

* Güçlendirilmiş yeni modelin performans analizlerinin gerçekleştirilmesi

* Güçlendirilmiş yapı performansının yeterlilik kontrolü

* Güçlendirme uygulama projesinin hazırlanması

* Proje inşaat maliyetinin hesaplanması ve bu sonucun incelenmesiyle yapının yıkılıp baştan yapılmasına veya daha uygun bir çözümse, hazırlanan güçlendirme projesinin hayata geçirilmesine karar verilmesi.

İncelenen binaların kullanım amacı ve mimari yapıları dikkate alındığında, mevcut betonarme çerçeveler içine betonarme perde ilavesi ile güçlendirilme yapılmasının ayrıca gevrek kolonların mantolama işlemi ile onarılmasının uygun bir yöntem olduğuna karar verilmiştir [13].

\subsection{Orta ve Büyük Ölçekli Bir Deprem Etkisi Altında Güçlendirilmiş Yapıların Performans Analizleri}

Güçlendirilmiş durum sonrasında yapılan performans analizleri sonucunda 50 yilda aşılma olasılığ1 \%10 olan orta ölçekli muhtemel bir deprem etkisi altında, binaya ait kiriş ve kolonlarda meydana gelen hasar yüzdeleri Vakıfbank Ortaokulu için Çizelge 13 ve Çizelge 14'de ve Sabancı İlkokulu için Çizelge 15 ve Çizelge 16'da belirtildiği gibidir.

Yine güçlendirilmiş durum sonrasında, 50 yılda aşılma olasılığ $\% 2$ olan büyük ölçekli muhtemel bir deprem etkisi altında, binaya ait kiriş ve kolonlarda meydana gelen hasar yüzdeleri Vakıfbank Ortaokulu için Çizelge 17 ve Çizelge 18'de Sabancı İlkokulu için ise Çizelge 19 ve Çizelge 20'de belirtildiği gibidir. 
Betonarme perde ilavesi ve gevrek kolonların manto ile onarılması sonucu ortaya çıan yapı modelleri ise Şekil 10-13’te verilmektedir.

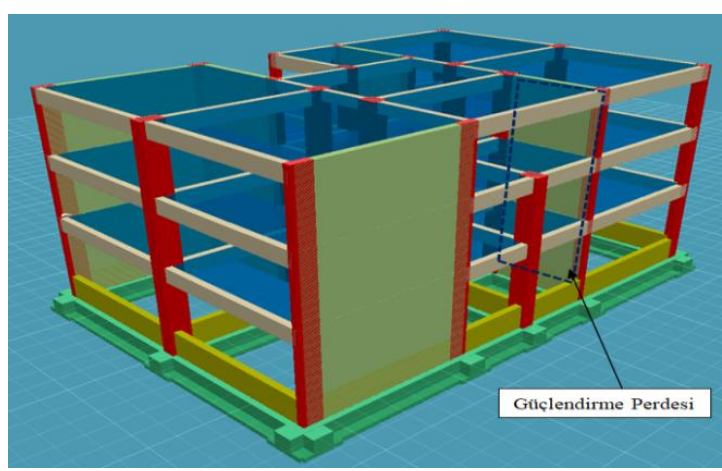

Şekil 10. Vakıfbank Ortaokulu güçlendirilmiş yapıya ait bilgisayar modeli

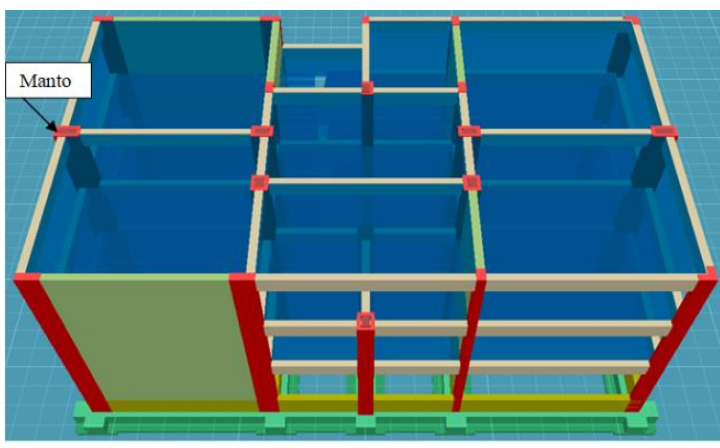

Sekil 11. Vakıfbank Ortaokulu onarım ve güçlendirme elemanları eklenmiş yapıya ait bilgisayar modeli

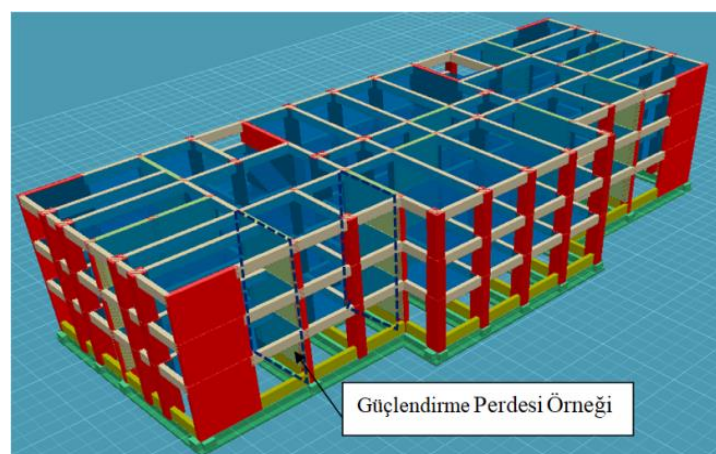

Sekil 12. Sabancı İlkokulu güçlendirilmiş yapıya ait bilgisayar modeli

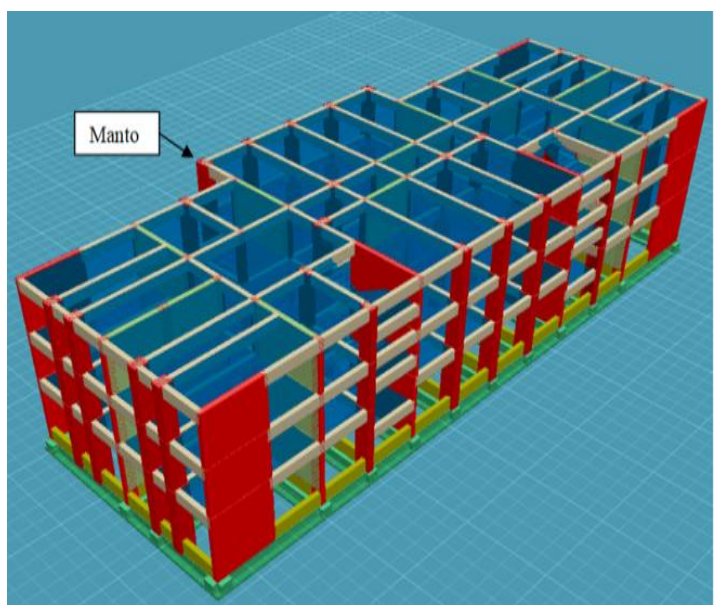

Şekil 13. Sabancı İlkokulu onarım ve güçlendirme elemanları eklenmiş yapıya ait bilgisayar modeli

Çizelge 13. Vakıfbank Ortaokulu için kiriş hasar yüzdeleri (Orta ölçekli deprem)

\begin{tabular}{|c|c|c|c|c|c|c|c|c|c|c|c|c|c|c|c|c|}
\hline \multirow{2}{*}{$\begin{array}{c}\text { KAT } \\
\text { NO }\end{array}$} & \multicolumn{4}{|c|}{$(-X)$} & \multicolumn{4}{|c|}{$(+X)$} & \multicolumn{4}{|c|}{$(-Y)$} & \multicolumn{4}{|c|}{$(+Y)$} \\
\hline & MH & BH & IH & GB & MH & BH & IH & GB & MH & BH & IH & GB & MH & BH & IH & GB \\
\hline 3 & 100 , & 0,0 & 0,0 & 0,0 & 100 & 0,0 & 0,0 & 0,0 & 90,0 & 10,0 & 0,0 & 0,0 & 90,0 & 10,0 & 0,0 & 0,0 \\
\hline 2 & 100 , & 0,0 & 0,0 & 0,0 & 100 , & 0,0 & 0,0 & 0,0 & 100 & 0,0 & 0,0 & 0,0 & 100 , & 0,0 & 0,0 & 0,0 \\
\hline 1 & 100 , & 0,0 & 0,0 & 0,0 & 100 & 0,0 & 0,0 & 0,0 & 100 & 0,0 & 0,0 & 0,0 & 100 & 0,0 & 0,0 & 0,0 \\
\hline Max. & 100 , & & & & & & & & & 10,0 & & & & & & \\
\hline
\end{tabular}

Çizelge 14. Vakıfbank Ortaokulu için kolon hasar yüzdeleri (Orta ölçekli deprem)

\begin{tabular}{|c|c|c|c|c|c|c|c|c|c|c|c|c|c|c|c|c|}
\hline \multirow{2}{*}{$\begin{array}{c}\text { KAT } \\
\text { NO }\end{array}$} & $\mathbf{4 H}$ & $\mathbf{B H}$ & $\mathbf{I H}$ & $\mathbf{G B}$ & $\mathbf{M H}$ & $\mathbf{B H}$ & $\mathbf{I H}$ & $\mathbf{G B}$ & $\mathbf{M H}$ & $\mathbf{B H}$ & $\mathbf{I H}$ & $\mathbf{G B}$ & $\mathbf{M H}$ & $\mathbf{B H}$ & $\mathbf{I H}$ & $\mathbf{G B}$ \\
\hline $\mathbf{3}$ & 100, & 0,0 & 0,0 & 0,0 & 100, & 0,0 & 0,0 & 0,0 & 99,8 & 0,2 & 0,0 & 0,0 & 99,7 & 0,3 & 0,0 & 0,0 \\
\hline $\mathbf{2}$ & 100, & 0,0 & 0,0 & 0,0 & 100, & 0,0 & 0,0 & 0,0 & 100, & 0,0 & 0,0 & 0,0 & 100, & 0,0 & 0,0 & 0,0 \\
\hline $\mathbf{1}$ & 100, & 0,0 & 0,0 & 0,0 & 100, & 0,0 & 0,0 & 0,0 & 100, & 0,0 & 0,0 & 0,0 & 100, & 0,0 & 0,0 & 0,0 \\
\hline Max. & $\mathbf{1 0 0}$ & & & & & & & & & & & & & $\mathbf{0 , 3}$ & & \\
\hline
\end{tabular}


Çizelge 15. Sabancı İlkokulu için kiriş hasar yüzdeleri (Orta ölçekli deprem)

\begin{tabular}{|c|c|c|c|c|c|c|c|c|c|c|c|c|c|c|c|c|}
\hline KAT & \multicolumn{4}{|c|}{$(-X)$} & \multicolumn{4}{|c|}{$(+X)$} & \multicolumn{4}{|c|}{$(-Y)$} & \multicolumn{4}{|c|}{$(+Y)$} \\
\hline NO & MH & BH & IH & GB & MH & $\mathbf{B H}$ & IH & GB & MH & BH & IH & GB & MH & $\mathbf{B H}$ & IH & GB \\
\hline 3 & 100 & 0,0 & 0,0 & 0,0 & 100 & 0,0 & 0,0 & 0,0 & 100 , & 0,0 & 0,0 & 0,0 & 100 , & 0,0 & 0,0 & 0,0 \\
\hline 2 & 100 , & 0,0 & 0,0 & 0,0 & 100 & 0,0 & 0,0 & 0,0 & 100 , & 0,0 & 0,0 & 0,0 & 100 , & 0,0 & 0,0 & 0,0 \\
\hline 1 & 100 & 0,0 & 0,0 & 0,0 & 100 & 0,0 & 0,0 & 0,0 & 100 & 0,0 & 0,0 & 0,0 & 100 & 0,0 & 0,0 & 0,0 \\
\hline Max. & 100 , & & & & & & & & & & & & & & & \\
\hline
\end{tabular}

Çizelge 16. Sabancı İlkokulu için kolon hasar yüzdeleri (Orta ölçekli deprem)

\begin{tabular}{|c|c|c|c|c|c|c|c|c|c|c|c|c|c|c|c|c|}
\hline $\begin{array}{c}\text { KAT } \\
\text { NO }\end{array}$ & $\mathbf{M H}$ & $\mathbf{B H}$ & $\mathbf{I H}$ & $\mathbf{G B}$ & $\mathbf{M H}$ & $\mathbf{B H}$ & $\mathbf{I H}$ & $\mathbf{G B}$ & $\mathbf{M H}$ & $\mathbf{B H}$ & $\mathbf{I H}$ & $\mathbf{G B}$ & $\mathbf{M H}$ & $\mathbf{B H}$ & $\mathbf{I H}$ & $\mathbf{G B}$ \\
\hline $\mathbf{3}$ & 100, & 0,0 & 0,0 & 0,0 & 100, & 0,0 & 0,0 & 0,0 & 99,9 & 0,1 & 0,0 & 0,0 & 99,9 & 0,1 & 0,0 & 0,0 \\
\hline $\mathbf{2}$ & 100, & 0,0 & 0,0 & 0,0 & 100, & 0,0 & 0,0 & 0,0 & 100, & 0,0 & 0,0 & 0,0 & 100, & 0,0 & 0,0 & 0,0 \\
\hline $\mathbf{1}$ & 100, & 0,0 & 0,0 & 0,0 & 100, & 0,0 & 0,0 & 0,0 & 100, & 0,0 & 0,0 & 0,0 & 100, & 0,0 & 0,0 & 0,0 \\
\hline Max. & $\mathbf{1 0 0}$ & & & & & & & & & & & & & $\mathbf{0 , 1}$ & & \\
\hline
\end{tabular}

Çizelge 17. Vakıfbank Ortaokulu için kiriş hasar yüzdeleri (Büyük ölçekli deprem)

\begin{tabular}{|c|c|c|c|c|c|c|c|c|c|c|c|c|c|c|c|c|}
\hline $\begin{array}{c}\text { KAT } \\
\text { NO }\end{array}$ & $\mathbf{M H}$ & $\mathbf{B H}$ & $\mathbf{I H}$ & $\mathbf{G B}$ & $\mathbf{M H}$ & $\mathbf{B H}$ & $\mathbf{I H}$ & $\mathbf{G B}$ & $\mathbf{M H}$ & $\mathbf{B H}$ & $\mathbf{I H}$ & $\mathbf{G B}$ & $\mathbf{M H}$ & $\mathbf{B H}$ & $\mathbf{I H}$ & $\mathbf{G B}$ \\
\hline $\mathbf{3}$ & 70,0 & 30,0 & 0,0 & 0,0 & 100, & 0,0 & 0,0 & 0,0 & 70,0 & 20,0 & 10,0 & 0,0 & 70,0 & 30,0 & 0,0 & 0,0 \\
\hline $\mathbf{2}$ & 100, & 0,0 & 0,0 & 0,0 & 100, & 0,0 & 0,0 & 0,0 & 81,8 & 18,2 & 0,0 & 0,0 & 81,8 & 18,2 & 0,0 & 0,0 \\
\hline $\mathbf{1}$ & 100, & 0,0 & 0,0 & 0,0 & 100, & 0,0 & 0,0 & 0,0 & 54,5 & 45,5 & 0,0 & 0,0 & 63,6 & 36,4 & 0,0 & 0,0 \\
\hline Max. & & & & & $\mathbf{1 0 0}$ & & & & & $\mathbf{4 5 , 5}$ & $\mathbf{1 0 , 0}$ & & & & & \\
\hline
\end{tabular}

Çizelge 18. Vakıfbank Ortaokulu için kolon hasar yüzdeleri (Büyük ölçekli deprem)

\begin{tabular}{|c|c|c|c|c|c|c|c|c|c|c|c|c|c|c|c|c|}
\hline \multirow{2}{*}{$\begin{array}{c}\text { KAT } \\
\text { NO }\end{array}$} & $\mathbf{M H}$ & $\mathbf{B H}$ & $\mathbf{I H}$ & $\mathbf{G B}$ & $\mathbf{M H}$ & $\mathbf{B H}$ & $\mathbf{I H}$ & $\mathbf{G B}$ & $\mathbf{M H}$ & $\mathbf{B H}$ & $\mathbf{I H}$ & $\mathbf{G B}$ & $\mathbf{M H}$ & $\mathbf{B H}$ & $\mathbf{I H}$ & $\mathbf{G B}$ \\
\hline $\mathbf{3}$ & 100, & 0,0 & 0,0 & 0,0 & 100, & 0,0 & 0,0 & 0,0 & 99,8 & 0,0 & 0,2 & 0,0 & 99,7 & 0,0 & 0,3 & 0,0 \\
\hline $\mathbf{2}$ & 99,9 & 0,1 & 0,0 & 0,0 & 100, & 0,0 & 0,0 & 0,0 & 99,8 & 0,2 & 0,0 & 0,0 & 99,7 & 0,3 & 0,0 & 0,0 \\
\hline $\mathbf{1}$ & 100, & 0,0 & 0,0 & 0,0 & 100, & 0,0 & 0,0 & 0,0 & 100, & 0,0 & 0,0 & 0,0 & 78,5 & 21,5 & 0,0 & 0,0 \\
\hline Max. & $\mathbf{1 0 0}$ & & & & & & & & & & & & & $\mathbf{2 1 , 5}$ & $\mathbf{0 , 3}$ & \\
\hline
\end{tabular}

Çizelge 19. Sabancı İlkokulu için kiriş hasar yüzdeleri (Büyük ölçekli deprem)

\begin{tabular}{|c|c|c|c|c|c|c|c|c|c|c|c|c|c|c|c|c|}
\hline $\begin{array}{c}\text { KAT } \\
\text { NO }\end{array}$ & $\mathbf{M H}$ & $\mathbf{B H}$ & $\mathbf{I H}$ & $\mathbf{G B}$ & $\mathbf{M H}$ & $\mathbf{B H}$ & $\mathbf{I H}$ & $\mathbf{G B}$ & $\mathbf{M H}$ & $\mathbf{B H}$ & $\mathbf{I H}$ & $\mathbf{G B}$ & $\mathbf{M H}$ & $\mathbf{B H}$ & $\mathbf{I H}$ & $\mathbf{G B}$ \\
\hline $\mathbf{3}$ & 100, & 0,0 & 0,0 & 0,0 & 100, & 0,0 & 0,0 & 0,0 & 94,3 & 5,7 & 0,0 & 0,0 & 94,3 & 5,7 & 0,0 & 0,0 \\
\hline $\mathbf{2}$ & 100, & 0,0 & 0,0 & 0,0 & 100, & 0,0 & 0,0 & 0,0 & 94,3 & 5,7 & 0,0 & 0,0 & 91,4 & 8,6 & 0,0 & 0,0 \\
\hline $\mathbf{1}$ & 100, & 0,0 & 0,0 & 0,0 & 100, & 0,0 & 0,0 & 0,0 & 100, & 0,0 & 0,0 & 0,0 & 85,7 & 14,3 & 0,0 & 0,0 \\
\hline Max. & $\mathbf{1 0 0}$ & & & & & & & & & & & & & $\mathbf{1 4 , 3}$ & & \\
\hline
\end{tabular}

Çizelge 20. Sabancı İlkokulu için kolon hasar yüzdeleri (Büyük ölçekli deprem)

\begin{tabular}{|c|c|c|c|c|c|c|c|c|c|c|c|c|c|c|c|c|}
\hline \multirow{2}{*}{$\begin{array}{c}\text { KAT } \\
\text { NO }\end{array}$} & \multicolumn{9}{|c|}{$\mathbf{( - X )}$} & \multicolumn{6}{|c|}{$\mathbf{( + X )}$} & \multicolumn{4}{|c|}{$\mathbf{( - Y )}$} & \multicolumn{4}{|c|}{$\mathbf{( + Y )}$} \\
\hline $\mathbf{3}$ & $\mathbf{M H}$ & $\mathbf{B H}$ & $\mathbf{I H}$ & $\mathbf{G B}$ & $\mathbf{M H}$ & $\mathbf{B H}$ & $\mathbf{I H}$ & $\mathbf{G B}$ & $\mathbf{M H}$ & $\mathbf{B H}$ & $\mathbf{I H}$ & $\mathbf{G B}$ & $\mathbf{M H}$ & $\mathbf{B H}$ & $\mathbf{I H}$ & $\mathbf{G B}$ \\
\hline $\mathbf{2}$ & 100, & 0,0 & 0,0 & 0,0 & 100, & 0,0 & 0,0 & 0,0 & 99,9 & 0,0 & 0,1 & 0,0 & 99,9 & 0,0 & 0,0 & 0,0 \\
\hline $\mathbf{1}$ & 91,8 & 8,0 & 0,0 & 0,0 & 100, & 0,0 & 0,0 & 0,0 & 100, & 0,0 & 0,0 & 0,0 & 100, & 0,0 & 0,0 & 0,0 \\
\hline Max. & $\mathbf{1 0 0}$, & & & & & $\mathbf{8 , 2}$ & & & & & $\mathbf{0 , 1}$ & & & & & \\
\hline
\end{tabular}




\section{SONUÇLAR}

Yapılan performans analizleri sonucunda ele alınan her iki yapının da mevcut halleriyle 2 . derece deprem bölgelerinde [14] meydana gelmesi muhtemel orta ve büyük ölçekli deprem etkileri altında yeterli deprem güvenliğine sahip olmadığ anlaşılmıştır.

Elde edilen sonuçlar yönetmelik koşulları dikkate alınarak incelendiğinde, güçlendirilmiş binaların orta ölçekli bir deprem etkisi altında "Hemen Kullanım" performans düzeyini, büyük ölçekli bir deprem etkisinde ise "Can Güvenliği" performans düzeyini sağladığını göstermektedir.

Bahsi geçen yapılar için güçlendirme öncesi ve sonrası durum Çizelge 21 ve Çizelge 22 'de belirtilmiştir.

Bakanlığın belirlediği 3B grubu yapılar kategorisinde olan yapıların yeniden yapım yaklaşık maliyetleri ve güçlendirilmeleri halinde maliyetleri hesaplanmıştır. Genel anlayış bu oranın 25-30 yillık yapılar için \%40’1 geçmesi durumunda yapının yıkılıp baştan yapılması, \%40'ın altında kalması durumunda ise güçlendirme projesinin hayata geçirilmesi yönündedir [15].

Maliyetlerin birbirlerine oranlanması sonucunda:

Vakıfbank ortaokulunun yıkılıp yeni baştan yapilmasındansa, güçlendirme projesinin uygulamaya konulmasının daha uygun ve ekonomik bir çözüm olduğu anlaşılmaktadır.

Sabancı ilkokulunda ise belirlenen maliyet oranı dikkate alındığında güçlendirmenin uygun ve ekonomik bir çözüm olmayacağı, binanın yıkılıp yeni baştan yapılmasının daha uygun olacağ anlaşılmaktadır.

Son olarak; ülkemizde hızlı bir yöntem olan, patlayıcı kullanılarak yıkım yapılması yerine iş makineleriyle uzun bir süreç alan yıkım işlemleri gerçekleştirilmektedir. Bahsi geçen maliyet oranlaması tam olarak \%40 seviyesinde ise hangi seçeneğin daha fazla zaman alacağı vb. etmenler değerlendirilerek karşıllaştırma yapılması mümkündür [16].

Çizelge 21. Güçlendirme çalışması sonuçları

\begin{tabular}{|l|l|}
\hline Yapının Adı: & Vakıfbank \\
\hline Güçlendirme ve Onarım Yöntemi & $\begin{array}{l}\text { BA Perde } \\
\text { İlavesi/Manto }\end{array}$ \\
\hline $\begin{array}{l}\text { Güçlendirme Elemanı Beton } \\
\text { Kalitesi/Donatı Tipi }\end{array}$ & C30/BÇIII \\
\hline Yapı Güçlendirme Maliyeti & $120.000 \mathrm{TL}$ \\
\hline Yapı Yeniden Yapım Maliyeti & $725.000 \mathrm{TL}$ \\
\hline $\begin{array}{l}\text { Güçlendirme Maliyeti/Yeniden } \\
\text { Yapım Maliyeti }\end{array}$ & $\mathbf{\%} \mathbf{1 6 , 5 5}<\% \mathbf{4 0}$ \\
\hline \multirow{4}{*}{$\begin{array}{l}\text { Mevcut Betonarme Perde En Kesit } \\
\text { Alanı/Kat Alanı }\end{array}$} & $\mathrm{X}$ Yönü: \\
\cline { 2 - 2 } & 0,014 \\
\hline \multirow{4}{*}{$\begin{array}{l}\text { Güçlendirme Perdesi En Kesit } \\
\text { Alanı/Kat Alanı }\end{array}$} & 0,0094 \\
\hline & $\mathrm{X}$ Yönü: \\
\cline { 2 - 2 } & - \\
\cline { 2 - 2 } & Y Yönü: \\
\cline { 2 - 2 } & 0,0045 \\
\hline \multirow{4}{*}{$\begin{array}{l}\text { Güçlendirilmiş Durum Toplam } \\
\text { Perde En Kesit Alanı/Kat Alanı }\end{array}$} & $\mathrm{X}$ Yönü: \\
\cline { 2 - 2 } & 0,014 \\
\cline { 2 - 2 } & Y Yönü: \\
\cline { 2 - 2 } & 0,0139 \\
\hline
\end{tabular}

Çizelge 22. Güçlendirme çalışması sonuçları

\begin{tabular}{|l|l|}
\hline Yapının Adı: & Sabancı İlk. \\
\hline Güçlendirme ve Onarım Yöntemi & $\begin{array}{l}\text { BA Perde } \\
\text { İlavesi/Manto }\end{array}$ \\
\hline $\begin{array}{l}\text { Güçlendirme Elemanı Beton } \\
\text { Kalitesi/Donatı Tipi }\end{array}$ & C30/BÇIII \\
\hline Yapı Güçlendirme Maliyeti & $635.000 \mathrm{TL}$ \\
\hline Yapı Yeniden Yapım Maliyeti & $1.530 .000 \mathrm{TL}$ \\
\hline $\begin{array}{l}\text { Güçlendirme Maliyeti/Yeniden } \\
\text { Yapım Maliyeti }\end{array}$ & $\mathbf{\% 4 1 , 5 > \% 4 0}$ \\
\hline \multirow{4}{*}{$\begin{array}{l}\text { Mevcut Betonarme Perde En Kesit } \\
\text { Alanı/Kat Alanı }\end{array}$} & X Yönü: \\
\cline { 2 - 2 } & 0,00688 \\
\cline { 2 - 2 } & Y Yönü: \\
\cline { 2 - 2 } & 0,00432 \\
\hline \multirow{4}{*}{$\begin{array}{l}\text { Güçlendirme Perdesi En Kesit } \\
\text { Alanı/Kat Alanı }\end{array}$} & $\mathrm{X}$ Yönü: \\
\cline { 2 - 2 } & 0,00732 \\
\cline { 2 - 2 } & Y Yönü: \\
\cline { 2 - 2 } & 0,00935 \\
\hline \multirow{4}{*}{$\begin{array}{l}\text { Güçlendirilmiş Durum Toplam } \\
\text { Perde En Kesit Alanı/Kat Alanı }\end{array}$} & $\mathrm{X}$ Yönü: \\
\cline { 2 - 2 } & 0,0142 \\
\cline { 2 - 2 } & Y Yönü: \\
\cline { 2 - 2 } & 0,01367 \\
\hline
\end{tabular}




\section{TEŞEKKÜR}

$\mathrm{Bu}$ çalışma “Çukurova Üniversitesi Bilimsel Araştırma Projeleri Birimi” tarafindan desteklenmiştir. (Proje No: FBA-2017-9411).

\section{KAYNAKLAR}

1. Arslan, M.H., Korkmaz, H.H., 2007. What is to be Learned from Damage and Failure of Reinforced Concrete Structures During Recent Earthquakes in Turkey? Engineering Failure Analysis 14, 1-22.

2. Sezen H., Whittaker AS., Elwood KJ., Khalid, M. 2003. Performance of Reinforced Concrete Buildings During the August 17, 1999 Kocaeli, Turkey Earthquake and Seismic Design and Construction Practise in Turkey. Eng Struct 25(1), 103-14.

3. Dogangun, A., 2004. Performance of Reinforced Concrete Buildings During the May 1, 2003 Bingol Earthquake in Turkey. Engineering Structures, 26(6), 841-56.

4. Bruneau M., 2002. Building Damage from the Marmara, Turkey Earthquake of August 17, 1999. Journal of Seismology, 6(3), 357-77.

5. FEMA 356 Prestandard and Commentary for the seismic rehabilitation of buildings, Federal Emergency Management Agency, November 2000.

6. Japan International Cooperation Agency. Study on a Disaster Prevention/Mitigation Basic Plan in Istanbul Including Seismic Microzonation in the Republic of Turkey. Report FEMA 273 (Guidelines) and Report 274 (Commentary), Washington, DC, 1997.

7. Deneme, İ.Ö., Yerli, H.R., 2002. Betonarme Yapılarda Deprem Hasarlarının Belirlenmesi ve Güçlendirme Projesi Uygulama Örneği, Çukurova Üniversitesi Müh. Mim. Fak. Dergisi, 17, 21-30.

8. Turkish Earthquake Code: Specifications for Structures to be Built in Disaster Areas. Ankara, Turkey: Earthquake Research Department, General Directorate of Disaster Affairs, Ministry of Public Works and Settlement; 2007.

9. Kandilli Observatory and Earthquake Research Institute (KOERI). The Novem- ber 09, 2011
Edremit-Van, Turkey earthquake (ML1/4 5.6). Preliminary report. Istanbul, Turkey: Department of Earthquake Engineering, Bogazici University, 2011.

10. Celep, Z., Kumbasar, N., 2000. Deprem Mühendisliğine Giriş ve Depreme Dayanıklı Yapı Tasarımı, İTÜ Yayınları, İstanbul, 596.

11. Hatzigeorgiou, GD., 2010. Ductility Demands Control under Multiple Earthquakes using Appropriate Force Reduction Factors. Journal of Earthquake and Tsunami, 4(3), 231-250.

12. Istanbul Technical University. Van Ilinde Bulunan MEB Okul Binalarının Hasar Durumlarına ait Rapor. ITU technical, report; 2011 [in Turkish].

13. Celep, Z., 2002. Mevcut Betonarme Binaların Deprem Güvenliğinin Belirlenmesi ve Güçlendirilmesinde Genel Kurallar, Prof. Dr. Kemal Özden'i Anma Semineri, İ.T.Ü., İstanbul.

14. Earthquake Department of the Disaster and Emergency Management Pre-sidency (AFAD). Ankara, Turkey, 2018.

15. Mutlu, A.H., 2015. Mevcut Yapıların Güçlendirilmesi ya da Yıkılmasına Karar Verilmesi Aşamasında Göz Önüne Alınması Gereken Kriterler. 3. Türkiye Deprem Mühendisliği ve Sismoloji Konferansı 14-16 Ekim 2015, DEÜ, İzmir.

16. Pun, S.K., Liu, C., Langston, C., 2006. Case Study of Demolition Costs of Residential Buildings, Construction Management and Economics, 24:(9), 967-976. 